\title{
PENETAPAN KADAR ß-KAROTEN PADA BEBERAPA JENIS \\ CABE (Genus Capsicum) DENGAN METODE SPEKTROFOTOMETRI TAMPAK
}

\author{
DETERMINATION OF ß-CAROTENE IN SOME TYPES \\ OF CHILI (Genus Capsicum) USING VISIBLE \\ SPECTROPHOTOMETRY METHOD
}

\author{
Tri Octaviani, Any Guntarti, Hari Susanti \\ Fakultas Farmasi Universitas Ahmad Dahlan Yogyakarta \\ Jl. Prof. Dr. Soepomo, Janturan, Yogyakarta \\ Email: any_guntarti@yahoo.co.id
}

\begin{abstract}
ABSTRAK
Beta karoten merupakan provitamin A yang berperan penting bagi pembentukan vitamin A. Sebagian besar sumber vitamin A adalah ß-karoten. Dalam tubuh ß-karoten akan diubah menjadi vitamin $\mathrm{A}$. Cabe yang dianggap sebagai bahan pangan yang sangat penting merupakan sumber ß-karoten yang sangat baik. Penelitian ini dilakukan untuk mengetahui kandungan ßkaroten dalam cabe dengan metode spektrofotometri tampak. Cabe segar yang telah dihaluskan diekstraksi dengan campuran heksana:aseton:etanol (2:1:1) v/v dengan metode maserasi. Setelah proses ekstraksi selesai ditambahkan akuabidestilata. Hasil ekstraksi berupa fase non polar dipisahkan, kemudian diuapkan sampai kering. Residu yang diperoleh selanjutnya digunakan untuk analisis kualitatif dan kuantitatif. Analisis kualitatif ß-karoten dengan metode Carr-Price. Penetapan kadar ß-karoten dilakukan dengan metode spektrofotometri tampak pada panjang gelombang 452,4 nm. Hasil uji kualitatif menunjukkan bahwa dalam cabe merah besar (Capsicum annuum L. Var. abreviatum Fingerhuth), cabe merah keriting (Capsicum annuum L. Var. Longum sendt) dan cabe rawit teridentifikasi adanya ß-karoten. Dari penelitian diperoleh hasil kadar rata-rata ß-karoten pada cabe merah besar sebesar $(10,54 \pm 0,07) \mathrm{mg} / 100 \mathrm{~g}$, cabe merah keriting sebesar $(5,57 \pm 0,13) \mathrm{mg} / 100 \mathrm{~g}$ dan cabe rawit sebesar $(0,36 \pm 0,01) \mathrm{mg} / 100 \mathrm{~g}$. Hasil analisis statistik dengan uji LSD hasil kadar ß-karoten dalam cabe merah besar, cabe merah keriting dan cabe rawit adalah berbeda bermakna (P.0,05).
\end{abstract}

Kata kunci : $ß$-karoten, cabe merah besar, cabe merah keriting, cabe rawit, spektrofotometri visibel.

\begin{abstract}
Beta carotene is provitamin essential role for vitamin A formation. Most of vitamin A sources are $\beta$-carotene. In the body, ß-carotene will be converted into vitamin A. Chilies are considered as one of the essential food. Chillies are known as very good sources of ß-carotene. Therefore, it is important to conduct a research in order to observe the content of ß-carotene in the chillies using visible spectrophotometry. Fresh chillies were extracted with a mixture of hexane:acetone:ethanol (2:1:1) v/v using a maceration method. After the extraction process was complete, aquabidest was added. The extraction result was non-polar phase. It was separated and evaporated. The residue was further subjected to qualitative and quantitative analysis
\end{abstract}


obtained. Qualitative analysis by using Carr-Price method. Determination of $\beta$-carotene was conducted using visible spectrophotometry method at $452,4 \mathrm{~nm}$. The qualitative test results showed that the Capsicum annuum L. Var. abreviatum Fingerhuth, Capsicum annuum L. Var. Longum sendt) and Capsicum frutescens L. contain ß-carotene. From the research, it was obtained that the average levels of ß-carotene on the Capsicum annuum L. Var. abreviatum Fingerhuth was $(10,54 \pm 0,07) \mathrm{mg} / 100 \mathrm{~g}$, Capsicum annuum L. Var. Longum sendt was $(5,57 \pm 0,13) \mathrm{mg} / 100 \mathrm{~g}$ and Capsicum frutescens L. was about $(0,36 \pm 0,01) \mathrm{mg} / 100 \mathrm{~g}$. Statistical analysis using LSD test of ß-carotene levels in the Capsicum annuum L. Var. abreviatum Fingerhuth, Capsicum annuum L. Var. Longum sendt) and Capsicum frutescens L. were significantly different at $\mathrm{P}$ of 0.05

Key words: ß-carotene, Capsicum annuum L. Var. abreviatum Fingerhuth, Capsicum annuum L. Var. Longum sendt, Capsicum frutescens L., visible spectrophotometry.

\section{PENDAHULUAN}

Vitamin merupakan suatu molekul organik yang sangat diperlukan tubuh untuk proses metabolisme dan memelihara kesehatan. Vitamin tidak dapat dibuat oleh tubuh manusia dalam jumlah yang cukup, oleh karena itu harus diperoleh dari luar yaitu dari bahan pangan atau sediaan vitamin seperti multivitamin yang dikonsumsi (Winarno, 1986).

Vitamin A dapat diperoleh dari buahbuahan berwarna kuning dan jingga sampai merah seperti pepaya, mangga, tomat, jeruk, jambu biji, alpukat dan cabe serta sayursayuran hijau. Beta karoten sebagai provitamin A merupakan unsur yang sangat potensial dan penting bagi vitamin A. Karena ß-karoten merupakan sumber vitamin A maka ketersediaan karoten perlu diketahui (De Man, 1997). Tujuan penelitian ini bertujuan untuk mengetahui kandungan ß-karoten di dalam cabe.

Cabe adalah salah satu bumbu masak yang banyak dikonsumsi masyarakat, sering dianggap bahan pangan yang sangat penting dan merupakan sumber pro-vitamin A yang sangat baik (Rubatzky dkk., 1999). Cabe sarat ß-karoten, kadarnya melebihi mangga, nanas, papaya, maupun semangka (Rubatzky dkk., 1999). Oleh karena itu perlu dilakukan penelitian untuk mengetahui kadar ß-karoten pada berbagai jenis cabe. Cabe mempunyai berbagai macam jenis. Dalam Tabel I disajikan 3 jenis cabe.

Karotenoid merupakan tetraterpenoid $\left(\mathrm{C}_{40}\right)$, merupakan golongan pigmen yang larut lemak dan tersebar luas, terdapat hampir di semua jenis tumbuhan, mulai dari bakteri sederhana sampai compositae yang berbunga kuning. Pada tumbuhan, karotenoid mempunyai dua fungsi yaitu sebagai figmen pembantu dalam fotosintesis dan sebagai pewarna dalam bunga dan buah (buah palsu mawar, tomat dan cabe capsium) (Harborne, 1996).

Saat ini terdapat lebih dari 300 karotenoid yang telah diketahui, yang paling umum terdapat pada tumbuhan tinggi hanya sedikit, kemungkinan terbesar adalah ßkaroten (Harborne, 1996). Struktur kimia senyawa ß-karoten terlihat seperti pada Gambar 1.

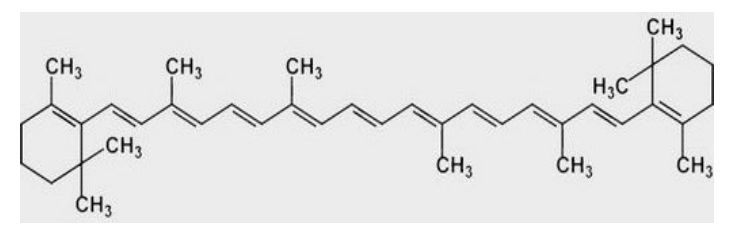

Gambar 1. Struktur ß-karoten (Robinson, 1995)

Karotenoid yang terkenal adalah hidrokarbon tak jenuh turunan likopen atau turunan likopen teroksigenase (ksantofil). Struktur kimia likopen berupa rantai panjang yang terdiri atas delapan satuan isoprena, 
merangkai dari kepala sampai ekor, sehingga terbentuk sistem konjugasi lengkap. Rangkaian ini merupakan kromofor yang menghasilkan warna. Isomer ß-karoten misalnya $\alpha$ - karoten hanya berbeda pada ikatan rangkapnya dalam satuan ujung siklik (Harbone, 1996). Beta karoten memiliki aktifitas tertinggi dibandingkan $\quad \gamma$-karoten dan $\alpha$-karoten. Hal ini karena terdapat perpanjangan rantai konjugasi sehingga mempunyai struktur polar yang lebih panjang (Prawirokusumo, 1991).

Ekstraksi adalah proses penarikan konstituen yang diinginkan dengan menggunakan pelarut yang dipilih dimana zat yang diinginkan dapat larut. Pelarut yang digunakan dipilih berdasarkan kemampuannya dalam melarutkan jumlah yang maksimum dari zat aktif dan seminimum mungkin bagi unsur yang tidak diinginkan (Ansel, 1989).

Maserasi merupakan cara penyarian yang sederhana. Maserasi dilakukan dengan cara merendam serbuk simplisia dalam cairan penyari. Cairan penyari akan menembus dinding sel dan masuk ke dalam rongga sel yang mengandung zat aktif, zat aktif akan larut dan karena adanya perbedaan konsentrasi antara larutan zat aktif didalam sel dengan yang diluar sel, maka larutan pekat didesak keluar. Peristiwa tersebut berulang sehingga terjadi keseimbangan konsentrasi antara larutan diluar sel dan didalam sel.

Maserasi digunakan untuk penyarian simplisia yang mengandung zat aktif yang mudah larut dalam cairan penyari, tidak mengandung cairan yang mudah mengembang dalam cairan penyari, tidak mengandung benzoit, stirak dan lain-lain. Cairan penyari yang digunakan dapat berupa air, etanol, air etanol, atau pelarut lain (Anonim, 1986).
Spektrofotometri UV-Vis adalah metode analisis berdasarkan interaksi antara radiasi elektromagnetik ultra violet dekat (190-380 nm) dan sinar tampak (380-780 nm) dengan memakai instrumen spektrofotometer dengan suatu materi (senyawa) (Mulja dan Suharman, 1995). Metode ini berdasarkan penyerapan sinar ultraviolet maupun sinar tampak yang menyebabkan terjadinya transisi elektron (perpindahan elektron dari tingkat energi yang rendah ketingkat energi yang lebih tinggi) (Hendayana dkk., 1994).

Apabila dua buah atom saling berikatan dan membentuk molekul maka akan terjadi tumpang tindih dua orbital dari kedua atom yang masing-masing mengandung satu elektron dan kemudian terbentuk orbital molekul (Gandjar, 1991). Hukum kuantitatif yang terkait dikenal dengan hukum LambertBeer. Menurut hukum Lambert-Beer :

$$
\begin{aligned}
\mathrm{T} & =\mathrm{I}_{\mathrm{t}} / \mathrm{I}_{\mathrm{o}}=10^{- \text {-.c.b }} \\
\mathrm{A} & =\log \mathrm{I} / \mathrm{T}=\epsilon . \mathrm{c.b}
\end{aligned}
$$

Dimana $\mathrm{T}=$ transmitan, $\mathrm{Io}=$ intensitas sinar yang datang, It = intensitas radiasi yang diteruskan, $\epsilon=$ absorbansi molar $\left(\right.$ Lt.mol $\left.{ }^{-1} \cdot \mathrm{cm}^{1}\right), \quad \mathrm{c}=$ konsentrasi $\left(\mathrm{mol} \cdot \mathrm{Lt}^{-1}\right)$, $\mathrm{b}=$ tebal larutan $(\mathrm{cm})$ dan $\mathrm{A}=$ absorban (Mulja dan Suharman, 1995).

Beberapa sumber radiasi polikromatik yang dipakai pada spektrofotometer UV-Vis adalah lampu deuterium, lampu tungsten dan lampu merkuri. Sumber radiasi tersebut akan mengeksitasi benda ke tingkat energi yang lebih tinggi. Benda atau materi akan kembali ke tingkat energi yang lebih rendah atau ke dasarnya, melepaskan foton dengan energi yang sesuai dengan perbedaan energi antara tingkat tereksitasi dengan tingkat dasar rendah. 
Tabel I. Berbagai jenis cabe dengan gambar, klasifikasi dan kandungan kimianya

\begin{tabular}{|c|c|c|c|}
\hline Hal & Cabe Merah & Cabe Keriting & Cabe Rawit \\
\hline \multicolumn{4}{|l|}{ Gambar } \\
\hline \multirow{8}{*}{ Klasifikasi } & Kingdom : Plantae & Kingdom : Plantae & Kingdom : Plantae \\
\hline & Divisi : Spermatophyta & Divisi : Spermatophyta & Divisi : Spermatophyta \\
\hline & Subdivisi : Angiospermae & Subdivisi : Angiospermae & Subdivisi : Angiospermae \\
\hline & Kelas : Dicotylodenae & Kelas : Dicotylodenae & Kelas : Dicotylodenae \\
\hline & Ordo : Solanales & : Solanales & : Solanales \\
\hline & Famili : Solanaceae & Famili : Solanaceae & Famili : Solanaceae \\
\hline & Genus : Capsicum & Genus : Capsicum & Genus : Capsicum \\
\hline & $\begin{array}{l}\text { Spesies : Capsicum } \\
\text { annuum L. Var. abreviatum } \\
\text { Fingerhuth } \\
\text { (Anonim, 2001). }\end{array}$ & $\begin{array}{l}\text { Spesies : Capsicum } \\
\text { annuum L. Longum sendt } \\
\text { (Anonim, 2001). }\end{array}$ & $\begin{array}{l}\text { Spesies: Capsicum } \\
\text { frutescens L. (Anonim, } \\
\text { 2001). }\end{array}$ \\
\hline Kandungan & $\begin{array}{l}\text { kapsaisin, vitamin C, } \\
\text { dammar, zat warna } \\
\text { kapsantin, kapsarubin, } \\
\text { zeasantin, kriptosantin, } \\
\text { lutein, karoten (Anonim, } \\
\text { 1979). }\end{array}$ & $\begin{array}{l}\text { Kapsaisin, vitamin C, } \\
\text { dammar, zat warna } \\
\text { kapsantin, kapsarubin, } \\
\text { zeasantin, kriptosantin, } \\
\text { lutein, karoten (Anonim, } \\
\text { 1979). }\end{array}$ & $\begin{array}{l}\text { Kapsaisin 0,02\%, alkaloid } \\
\text { atsiri, resin, minyak lemak, } \\
\text { vitamin C (Anonim, 1979) } \\
\text { dan karoten (Dalimarta, } \\
\text { 2000). }\end{array}$ \\
\hline
\end{tabular}

\section{METODE PENELITIAN}

Alat

Seperangkat alat spektrofotometer UVVis (Pharmaspec UV-1700 Shimadzu, Jepang), magnetik stirer, corong pisah, corong buchner, kertas aluminium foil, timbangan analitik, glassware.

\section{Bahan}

Bahan utama berupa Cabe merah besar (Capsicum annuum L. Var. abreviatum Fingerhuth) dari Temanggung dan diperoleh melalui PT. LION SUPERINDO Jl. Sultan Agung No.10 Yogyakarta, Cabe merah keriting (Capsicum annuum L Var. Longum sendt) dan cabe rawit (Capsicum frutescens L.) segar yang dipanen langsung dari kebunnya di Sleman. Bahan kimia yang digunakan adalah antimon triklorida p.a (E merck), ß-karoten p.a (Sigma), etanol p.a (E
Merck), heksana p.a (E Merck), aseton p.a (E Merck), kloroform p.a (E Merck), aquabidest.

\section{Jalannya Penelitian}

\section{Pembuatan larutan pereaksi untuk uji kualitatif ß-karoten}

Larutan antimon triklorida 25\% : Larutan antimon triklorida dibuat dengan melarutkan 2,5 gram antimon triklorida dalam kloroform sampai $10 \mathrm{~mL}$ (Andarwulan dan Koswara, 1992).

\section{Pengambilan sampel}

Sampel yang digunakan dalam penelitian ini yaitu cabe merah keriting (Capsicum annuum L Var. Longum sendt), cabe rawit (Capsicum frutescens L.) berasal dari Sleman dan cabe merah besar (Capsicum annuum L. Var. abreviatum Fingerhuth) yang berasal dari Temanggung melalui PT. LION 
SUPERINDO Jl. Sultan Agung No.10 Yogyakarta.

\section{Penyiapan sampel}

Sejumlah cabe segar dihaluskan dengan blender, kemudian ditimbang sebanyak 50 gram, dimasukkan ke dalam Erlenmeyer bertutup yang dilapisi dengan kertas

\section{Uji kualitatif ß-karoten}

Uji kualitatif dilakukan dengan uji tabung menggunakan larutan antimon triklorida $25 \%$ dalam kloroform. Hasil ekstraksi berupa larutan, diambil sejumlah 2 $\mathrm{mL}$, kemudian ditambahkan larutan antimon triklorida (Andarwulan dan Koswara, 1992).

\section{Uji kuantitatif ß-karoten \\ a. Pembuatan larutan baku}

Pembuatan larutan baku dibuat dengan menimbang seksama ß-karoten standar dilarutkan dengan etanol absolut p.a. hingga diperoleh konsentrasi larutan induk sebesar $1 \mathrm{mg} / \mathrm{mL}$.

\section{b. Penetapan operating time}

Larutan baku ß-karoten $50 \mu \mathrm{g} / \mathrm{mL}$ dibaca serapannya pada panjang gelombang $452 \mathrm{~nm}$ sampai diperoleh waktu serapan yang stabil.

\section{c. Penetapan panjang gelombang serapan maksimum}

Larutan baku ß-karoten $50 \mu \mathrm{g} / \mathrm{mL}$ dibaca serapannya pada panjang gelombang 350-550 nm.

\section{d. Penentuan kurva baku}

Penentuan kurva baku dibuat seri larutan baku ß-karoten $50 \mu \mathrm{g} / \mathrm{mL}$ yaitu $3,0 \mu \mathrm{g} / \mathrm{mL}, \quad 6,0 \mu \mathrm{g} / \mathrm{mL}, \quad 9,0 \mu \mathrm{g} / \mathrm{mL}, \quad 12,0$ $\mu \mathrm{g} / \mathrm{mL}, 15,0 \mu \mathrm{g} / \mathrm{mL}$, dibaca pada operating time dan panjang gelombang serapan maksimum yang diperoleh. aluminium foil pada bagian luar dan terlindungi dari cahaya. Ditambahkan $50 \mathrm{~mL}$ larutan (heksana:aseton:etanol $=2: 1: 1$ ) $\mathrm{v} / \mathrm{v}$, dikocok selama 30 menit dengan magnetic stirer, dan disaring dengan corong Buchner. Diambil bagian non polar dan selanjutnya digunakan untuk uji kualitatif dan uji kuantitatif.

\section{e. Pengukuran serapan}

Residu dari cabe merah, cabe merah keriting dan cabe rawit dimasukkan ke dalam labu takar 5,0 mL kemudian ditambah pelarut organik (etanol) sampai tanda batas dan dibaca serapannya.

\section{Analisis data}

Data kuantitatif yaitu kadar ß-karoten dalam cabe merah besar, cabe merah keriting dan cabe rawit diuji statistik dengan uji Kolmogorov Smirnov untuk mengetahui data tersebut terdistribusi normal atau tidak. Kemudian dilanjutkan dengan uji Levene untuk mengetahui varian homogen atau tidak. Jika data tersebut terdistribusi normal dan variannya homogen maka dilanjutkan dengan uji parametrik ANOVA, jika pada uji ANOVA terdapat perbedaan dilanjutkan dengan Post Hoct Test untuk melihat dimana letak perbedaan tersebut. Jika data tersebut tidak terdistribusi normal atau variannya tidak homogen maka diuji dengan non parametrik Kruskal Wallis. Jika terdapat perbedaan yang bermakna dilanjutkan dengan uji Mann Whitney.

\section{HASIL DAN PEMBAHASAN}

\section{Pengumpulan bahan}

Cabe merah keriting (Capsicum annuum L Var. Longum sendt) dan cabe rawit (Capsicum frutescens L.) yang digunakan dalam penelitian ini adalah cabe segar yang dipanen langsung dari kebunnya di Sleman sedangkan cabe merah besar (Capsicum annuum L. Var. abreviatum Fingerhuth) 
berasal dari Temanggung dan diperoleh melalui PT. LION SUPERINDO Jl. Sultan Agung No.10 Yogyakarta. Cabe merah besar mudah terkena serangan hama dan penyakit sehingga di Sleman tidak ada yang menanam cabe ini. Tetapi dapat dipastikan cabe yang diperoleh cabe segar sehingga baik digunakan untuk penelitian.

\section{Preparasi sampel}

Cabe yang telah dihaluskan diekstraksi dengan tujuan untuk memisahkan ß-karoten dari senyawa lain dan digunakan heksana : aseton : etanol karena sifat dari ß-karoten yang larut dalam pelarut non polar. Hasil residu dilarutkan dalam etanol dan dilakukan pengenceran yang selanjutnya digunakan untuk uji kualitatif dan uji kuantitatif.

\section{Uji kualitatif}

Uji kualitatif dilakukan dengan Metode Carr-Price, dengan prinsip pembentukan warna biru sebagai hasil reaksi antara provitamin A dengan antimon triklorida dalam kloroform terbentuk warna biru. Hasil uji kualitatif disajikan pada Gambar 2.

Uji kualitatif ini diperjelas dengan hasil spektra pada sampel yang menunjukkan kemiripan dengan spektra standar terdapat puncak pada daerah sekitar 350-550 nm.

\section{Uji kuantitatif}

Uji kuantitatif dimaksudkan untuk menetapakan kadar ß-karoten. Hasil tahapan diperoleh bahwa waktu operasi (operating time) sangat stabil karena tidak terjadi reaksi atau reaksi pembentukan warna. Panjang gelombang serapan maksimum adalah 452,4 nm. Hasil pengukuran kurva baku disajikan pada Tabel II.

\begin{tabular}{|c|c|c|}
\hline \multirow[t]{7}{*}{ Tabel II. } & $\begin{array}{l}\text { Serapan } \\
\text { standar } \\
\text { konsentrasi }\end{array}$ & $\begin{array}{c}\text { larutan } \\
\text { pada }\end{array}$ \\
\hline & $\mathrm{C}(\mu \mathrm{g} / \mathrm{mL})$ & $\begin{array}{l}\text { Serapan } \\
\text { (A) }\end{array}$ \\
\hline & 3 & 0,331 \\
\hline & 6 & 0,446 \\
\hline & 9 & 0,576 \\
\hline & 12 & 0,713 \\
\hline & 15 & 0,855 \\
\hline
\end{tabular}

Berdasarkan data-data pada Tabel II diperoleh persamaan regresi linier yang menyatakan hubungan antara konsentrasi larutan ß-karoten standar dengan serapan yaitu $\mathrm{Y}=0,0483 \mathrm{X}+0,1897$ dengan $\mathrm{r}=$ 0,9992, dimana $\mathrm{Y}$ adalah serapan dan $\mathrm{X}$ adalah konsentrasi dalam $\mu \mathrm{g} / \mathrm{mL}$. Setelah dibandingkan dengan koefisien korelasi (r) tabel $=0,959$ dengan taraf kepercayaan 99\% ternyata $r$ hitung $>r$ tabel, yang menunjukkan bahwa adanya hubungan yang signifikan antara konsentrasi larutan ß-karoten standar dengan serapan sehingga dapat digunakan untuk penetapan kadar ß-karoten dalam sampel. Hal ini dapat terlihat dari grafik kurva baku ß-karoten standar yang berbentuk garis lurus.

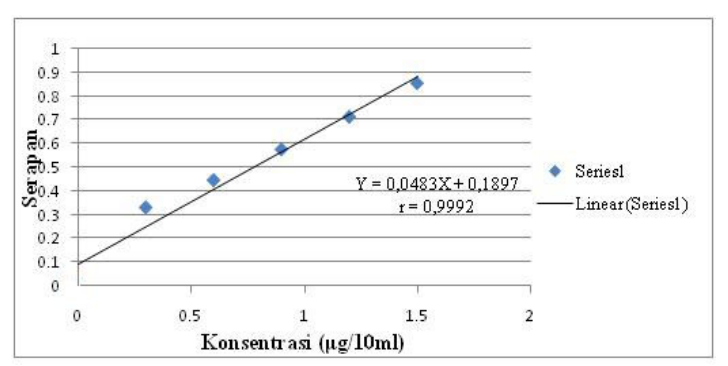

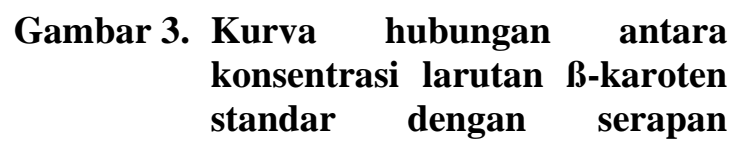




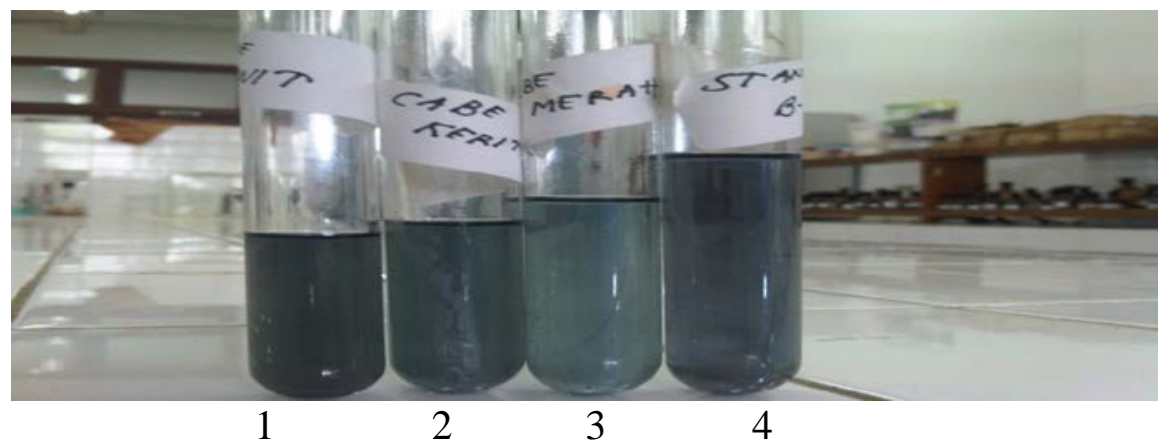

Gambar 2. Hasil uji kualitatif, pembentukan warna dengan antimon klorida , (1) Cabe rawit (Capsicum frutescens L.), (2) Cabe merah keriting (Capsicum annuum L Var. Longum sendt), (3) Cabe merah besar (Capsicum annuum L. Var. abreviatum Fingerhuth), (4) B-karoten standar

Tabel III. Hasil penetapan kadar B-karoten dalam sampel

\begin{tabular}{lcccc}
\hline \multicolumn{1}{c}{ Sampel } & No & Kadar $(\mathbf{m g} / \mathbf{1 0 0 g})$ & $\overline{\mathrm{X}} \pm \mathbf{S D}(\mathbf{m g} / \mathbf{1 0 0 g})$ & $\mathbf{C V}(\mathbf{\%})$ \\
\hline & 1 & 10,59 & & \\
Cabe merah besar & 2 & 10,62 & $10,54 \pm 0,07$ & 0,66 \\
& 3 & 10,55 & & \\
& 4 & 10,50 & & \\
Cabe merah keriting & 5 & 10,45 & $5,57 \pm 0,13$ & \\
& 1 & 5,71 & & \\
& 2 & 5,57 & & \\
& 3 & 5,41 & & \\
& 4 & 5,57 & & \\
& 5 & 5,46 & & \\
& 1 & 0,35 & & \\
\end{tabular}

Kadar ß-karoten dalam cabe merah besar (Capsicum annuum L. Var. abreviatum Fingerhuth), cabe merah keriting (Capsicum annuum L Var. Longum sendt) dan cabe rawit (Capsicum frutescens L.).

Dari hasil penelitian diketahui bahwa ßkaroten dalam cabe merah besar $>$ cabe merah keriting dan $>$ cabe rawit.

Hal ini ada hubungan langsung antara derajat kemerahan cabe dengan kadar ßkaroten, semakin merah cabe semakin tinggi kadar ß-karoten dan ini dipengaruhi antara lain oleh tingkat kematangan cabe. Warna merah biasanya seiring dengan kematangan cabe, sehingga faktor panen cabe yang diambil sangat menentukan kadar ß-karoten.

Hasil analisis statistik diawali dengan uji Kolmogorov Smirnov, hasil menunjukkan bahwa data kadar ß-karoten dalam cabe tesebut terdistribusi normal dengan nilai asymtot $0,485>0,01$. Dilanjutkan dengan uji Levene untuk mengetahui homogenitas varian dan diperoleh nilai Asymtot 0,737>0,01 sehingga diketahui varian data kadar $\beta$ karoten dalam cabe adalah homogen. Karena terdistribusi normal dilakukan uji parametrik Anova dan diperoleh nilai Asymtot signifikan $0,000<0,01$ yang menunjukkan bahwa kadar 


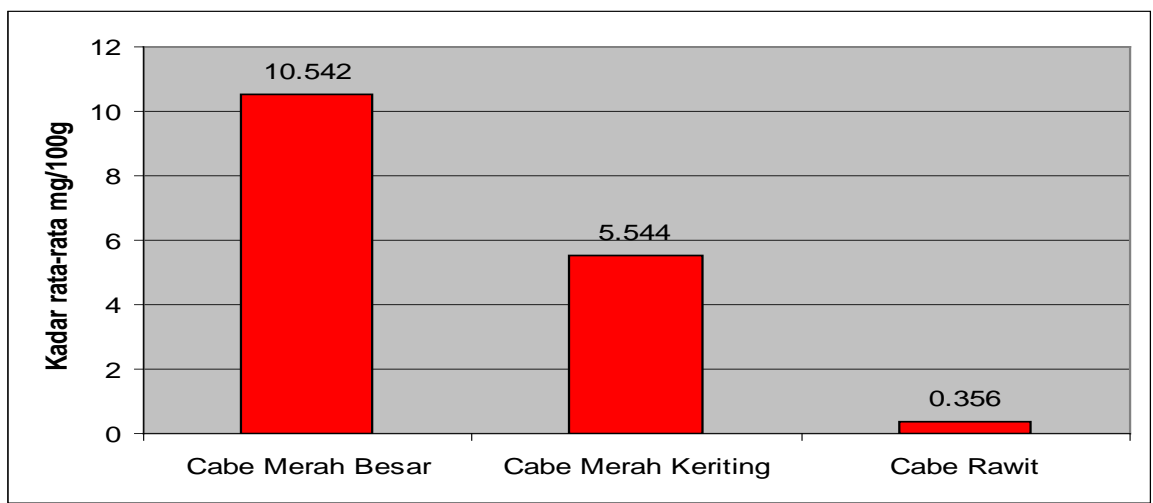

\section{Gambar 4. Grafik kadar ß-karoten rata-rata sampel dalam cabe dengan berbagai jenis}

ß-karoten antara cabe merah besar (Capsicum annuum L. Var. abreviatum Fingerhuth), cabe merah keriting (Capsicum annuum L Var. Longum sendt) dan cabe rawit (Capsicum frutescens L.) terdapat perbedaan yang bermakna. Dari hasil penelitian diketahui bahwa ß-karoten dalam cabe merah besar $>$ cabe merah keriting dan $>$ cabe rawit.

Hal ini ada hubungan langsung antara derajat kemerahan cabe dengan kadar ßkaroten, semakin merah cabe semakin tinggi kadar ß-karoten dan ini dipengaruhi antara lain oleh tingkat kematangan cabe. Warna merah biasanya seiring dengan kematangan cebe, sehingga faktor panen cabe yang diambil sangat menentukan kadar ß-karoten.

Hasil analisis statistik diawali dengan uji Kolmogorov Smirnov, hasil menunjukkan bahwa data kadar ß-karoten dalam cabe tesebut terdistribusi normal dengan nilai asymtot $0,485>0,01$. Dilanjutkan dengan uji Levene untuk mengetahui homogenitas varian dan diperoleh nilai Asymtot 0,737>0,01 sehingga diketahui varian data kadar ßkaroten dalam cabe adalah homogen.

Karena terdistribusi normal dilakukan uji parametrik Anova dan diperoleh nilai Asymtot signifikan $0,000<0,01$ yang menunjukkan bahwa kadar ß-karoten antara cabe merah besar (Capsicum annuum L. Var. abreviatum Fingerhuth), cabe merah keriting (Capsicum annuum L Var. Longum sendt) dan cabe rawit (Capsicum frutescens L.) terdapat perbedaan yang bermakna.

\section{KESIMPULAN}

Cabe merah besar (Capsicum annuum L. Var. abreviatum Fingerhuth), cabe merah keriting (Capsicum annuum L Var. Longum sendt) dan cabe rawit (Capsicum frutescens L.) mengandung $ß$-karoten. Kadar rata-rata ßkaroten pada cabe merah besar sebesar $(10,54 \pm 0,07) \mathrm{mg} / 100 \mathrm{~g}$, cabe merah keriting sebesar $(5,57 \pm 0,13) \mathrm{mg} / 100 \mathrm{~g}$ dan cabe rawit sebesar $(0,36 \pm 0,01) \quad \mathrm{mg} / 100 \mathrm{~g}$. Kadar $ß-$ karoten pada cabe merah besar, cabe merah keriting dan cabe rawit adalah berbeda bermakna.

\section{DAFTAR PUSTAKA}

Andarwulan, N., dan Koswara S., 1992, Kimia Vitamin, Institut Pertanian Bogor, hal 23-40.

Anonim, 1979, Materia Medika Indonesia, Jilid III, Dep.Kes. R.I., Jakarta, hal 46.

Anonim, 1986, Sediaan Galenik, Direktorat Jendral Pengawasan Obat dan Makanan, Dep.Kes. R.I, Jakarta, hal 10, 16, 26.

Anonim, 1996, AOAC edisi XVI, AOAC International, Mayland, USA, hal 638.

Ansel, H. C., 1989, Pengantar Bentuk Sediaan Farmasi, Edisi 4, UI Press, Jakarta, hal 605. 
De Man, J. M., 1997, Kimia Makanan, edisi kedua, Penerbit ITB Bandung, Bandung, hal 397.

Gandjar, I. G., 1991, Kimia Analisis Instrumental, Dep.Pendd. dan Keb. Fakultas Farmasi UGM, Yogyakarta, hal 15-25.

Harborne, J.B., 1996, Metode Fitokimia Penuntun Cara Modern Menganalisis Tumbuhan, Edisi II, ITB Bandung, hal 21-23, 123-125, 158, 161-164.

Hendayana, S., Kodorahman, A., Sumarna, A. A., dan Supritra, A., 1994, Kimia Analitik Instrument, Edisi I, hal 156160.
Mulja, H. dan Suharman, S., 1995, Analisis Instrumental, Airlangga University Press, Surabaya, hal 26-48.

Prawirokusumo, S., 1991, Biokimia Nutrisi (Vitamin), edisi I, BPFE, Yogyakarta, hal 90-91.

Robinson, T., 1995, Kandungan Organik tumbuhan tinggi, Penterjemah : Kosasih Padmawinat, Penerbit ITB, Bandung, hal 163.

Vincent, E., Rubatzky, Mas yamaguchi, 1999, Sayuran Dunia 3 , ITB Bandung hal 25.

Winarno, F. G., 1986, Kimia Pangan dan Gizi, Penerbit PT. Gramedia Pustaka Utama, Jakarta, hal 131-132. 